\title{
Quality of life of patients with lower limb amputation with prostheses
}

\author{
Qualidade de vida em pacientes com amputação \\ de membros inferiores e em uso de próteses
}

\author{
Denise Regina MATOS1 ${ }^{1}$ (D) 0000-0002-0866-4464 \\ Juliana Fákir NAVES ${ }^{1}$ iD) 0000-0002-0548-6797 \\ Tereza Cristina Cavalcanti Ferreira de ARAUJO' (iD) 0000-0002-5204-8124
}

\begin{abstract}
Quality of life is often acknowledged as an important outcome of rehabilitation programs for people with amputation. Despite the importance of the subject, the number of studies focusing on the multiplicity of factors influencing this matter is still limited. These assessments are increasingly needed to demonstrate changes related to intervention over time. In order to evaluate the quality of life of patients with lower limb amputation and wearing prostheses, a study was conducted with 49 patients followed in a rehabilitation hospital in the Midwest region of Brazil. A generic instrument (Medical Outcomes Study 36-Item Short-Form Health Survey) for quality of life assessment and Trinity Amputation and Prosthesis Experience Scale-Revised that is specific for people with amputation were used in addition to a functional assessment measure. The results showed that the time since amputation, male gender and below-knee amputations were predictors of a better perception of quality of life and better adjustment to amputation.
\end{abstract}

Keywords: Amputation; Quality of life; Prosthesis; Rehabilitation.

\section{Resumo}

Qualidade de vida é frequentemente reconhecida como um importante resultado de programas de reabilitação em pessoas com amputação. Apesar da importância do tema, o número de estudos centrados na multiplicidade de fatores que a influenciam ainda é restrito. Contudo, essas avaliações são cada vez mais necessárias para demonstrar mudanças

\footnotetext{
$\boldsymbol{\nabla} \boldsymbol{\nabla} \nabla$
}

1 Universidade de Brasília, Instituto de Psicologia, Departamento de Psicologia e Cultura. Campus Universitário Darcy Ribeiro, 70910-900, Brasília, DF, Brasil. Correspondence to: T.C.C.F. ARAUJO.E-mails: <araujotc@unb.br>, <dmatos65@gmail.com>.

Article based on the thesis of D.R. MATOS, entitled "Reabilitação e qualidade de vida em pessoas com amputação de membros inferiores".

Universidade de Brasilia, 2019.

How to cite this article

Matos, D. R., Naves, J. F., Araujo, T. C. C. F. (2020). Quality of life of patients with lower limb amputation with prostheses. Estudos de Psicologia (Campinas), 37, e190047. http://dx.doi.org/10.1590/1982-0275202037e190047 
relacionadas à intervenção ao longo do tempo. Com objetivo de avaliar a qualidade de vida de pacientes com amputação de membros inferiores e que fazem uso de próteses, realizou-se uma pesquisa com 49 pacientes acompanhados em um hospital de reabilitação, na Região Centro-Oeste, Brasil. Foram utilizados um instrumento genérico (Questionário Genérico de Avaliação de Qualidade de Vida) para avaliação de qualidade de vida, a Escala Trinity sobre a Experiência a Amputação e uso de Prótese-Versão revisada, que é específico para pessoas com amputação, e uma medida de avaliação funcional. Os resultados evidenciaram que o tempo desde a amputação, o fato de pertencer ao sexo masculino e as amputações abaixo do joelho foram fatores preditores de uma melhor percepção de qualidade de vida e de um melhor ajustamento à amputação.

Palavras-chave: Amputação; Qualidade de vida; Prótese; Reabilitação.

By definition, amputation is the process of removing a limb or part of it by sectioning one or more bones, while disarticulation is a surgery through the joint surface (Mohammed \& Shebl, 2014). Usually considered as a mutilating procedure, it should be understood by health professionals as well as patients, as a reconstruct or, since it is able to relieve pain and provide function improvement in relation to the maintenance of the compromised limb, when the procedure is properly indicated (Schnur \& Meier, 2014).

Among the listed causes for amputation, the most common are associated with complications of diabetes and peripheral arterial diseases in the lower limbs (Knezevic et al., 2015). The following are amputation traumatic causes: traffic accidents (motorcycle or car), agricultural machinery, electric shock or firearms. Cancer represents a rare causality compared to the other causes mentioned, being those as a result of malignant bone tumors, which included 6\% of all tumors in individuals under 20 years of age (Pasquina et al., 2014).

There is an increase in the number of cases not only associated with war in some countries, but mainly with the aging population, advances in medical treatments and increasing lifestyle-related diseases such as diabetes and peripheral vascular disease, as well as those that result from traffic accidents in large cities, which show an increasing trend compared to non-traumatic causes (Barbosa et al., 2016; Holzer et al., 2014).

Investigations of patients with limb amputation associated to psychosocial aspects have gained prominence in the literature in the last 10 years. Earlier studies were based primarily on the physical aspects of amputation. Study groups in the United Kingdom use the term Psychoprosthetics, which specifically refers to "prosthesis-related psychology", which is defined as the study of the psychological, social, and behavioral aspects of amputated patients and the associated rehabilitation process. A current trend is criticism of the use of "amputees" terminology, as it refers to losses rather than to the potential of those who have gone through limb extirpation. The recommended term is "person with amputation", which seeks to valuate the individual based on his or her specificities and abilities (Schaffalitzky, Gallagher, Desmond, \& MacLachlan, 2010). As a result of these publications, instruments for specific assessment of this population emerge, such as the Trinity Amputation and Prosthetic Experiences Scales (TAPES), which aim to specifically evaluate the quality of life of amputated individuals (Gallagher, Desmond, \& MacLachlan, 2005).

The use of quality of life measures that encompass a wide range of experiences should be encouraged and reflects a movement within the human and biological sciences to value broader parameters rather than just symptom control, decreased mortality or the increase in life expectancy. Quality of life allows us to understand fundamental aspects for each individual and can bring results that help in approaching and restructuring care programs (Akyol et al., 2013; Pocnet et al., 2016).

Patients with lower limb amputation highlight the importance of quality of life in defining a successful treatment outcome. Despite this importance, there is a relatively limited number of studies that assess the diversity of factors that influence quality of life of these individuals (Mohammed \& Shebl, 2014; Suckow et al., 2015).

Whereas quality of life is a multidimensional construct consisting of objective components (such as

2 behavior and environment) and subjective components (psychological well-being and life satisfaction), a 
serious illness can have a direct impact on a person's state of health, limiting his/her mobility and autonomy. On the other hand, the individuals' satisfaction with their own life may differ from that of other patients, even though they have the same disease due to their objective health and life conditions. Objective and subjective components are supposed to explain unique proportions of variance in people's quality of life (Pocnet et al., 2016).

Quality of life is influenced in a complex way by physical health, psychological state, level of independence, social relationship and environmental relations (Panzini et al., 2017). Among the domains of quality of life, it appears that psychological functioning and physical health are the most investigated subjects in health, since all studies evaluated one or both aspects. However, it has been observed that other domains are also becoming increasingly relevant and important, namely autonomy, interpersonal relationships, rights and physical, emotional and material well-being. (Counted, Possamai, \& Meade, 2018).

For patients with amputation, the perception of quality of life is more associated with pain, adaptation to the prosthesis and psychosocial well-being than with clinical or demographic variables such as age, gender, level and cause of amputation (Vaz, Roque, Pimentel, Rocha, \& Duro, 2012). The ability to walk is considered central to the perception of quality of life, as it directly impacts the ability to live independently (autonomy) and community participation (Davie-Smith, Coulter, Kennon, Wyke, \& Paul, 2017). Another study stresses the importance of maximizing mobility (whether or not using a prosthesis) in patients with lower limb loss, both for the associated immediate functional benefits and for their influence on other domains (Wurdeman, Stevens, \& Campbell, 2018).

Persons with amputation may report a reduction in their quality of life immediately after limb loss, but over time the response may change depending on their adaptation to the new condition, with moderate improvement as they live longer with the sequel (Asano, Rushton, Miller, \& Deathe, 2008).

In the national scenario, the rehabilitation of these patients has advanced in recent years, especially through multidisciplinary interventions and legal support in the public health system. However, there are still difficulties to be overcome, such as delays in referral for the starting of appropriate treatment and inclusion in rehabilitation programs, in addition to the socioeconomic difficulties that lead to abandonment of the prosthesis, with consequent failure in rehabilitation (Pasquina \& Sheehan, 2015; Silva, Rizzo, Gutierres Filho, Ramos, \& Deans, 2011). In Brazil, population statistical data are scarce. According to the 2010 Population Census, there are over 13 million people with motor disabilities (Instituto Brasileiro de Geografia e Estatística, 2011). Updated national statistics are required to schedule care services and public health policies. In this scenario, this survey may contribute to the scientific development in this area of knowledge and provide information to the institutions in their planning and evaluation of their assistance programs. Thus, this study was conducted to evaluate the quality of life of patients with lower limb amputations and prosthesis users in a rehabilitation hospital.

\section{Method}

\section{Participants}

This descriptive and cross-sectional study was conducted with a sample of 49 participants. These were invited to participate in the survey during the appointments for prosthesis adjustments or for the setting of new prosthesis, in the orthopedic workshop of a rehabilitation hospital, located in the Midwest region of Brazil. The orthopedic workshop is the place where orthoses and prostheses are produced with the help of a team composed of physiotherapists, occupational therapists, psychologists, physical education teachers and prosthetists, who monitor these patients over time.

Inclusion criteria were: patients over 18 years old, with lower limb amputation for more than six months, wearing prostheses and literate. 


\section{Instruments}

Generic Quality of Life Assessment Questionnaire - SF-36: This is a global quality of life assessment instrument, validated for Brazilian Portuguese language. It aims to achieve minimum standards necessary to allow comparisons between different groups involving general health concepts, not being specific for a particular disease, age or treatment group (Ware \& Sherbourne, 1992). It is multidimensional, consisting of 36 items that evaluate eight of the main health concepts (functional capacity, physical aspect, vitality, emotional aspect, social aspect, mental health, general health conditions and pain). High scores are associated with better perception of quality of life by the patient (Ciconelli, Ferraz, Santos, Meinão, \& Quaresma, 1999). It stands out with the highest number of occurrences appearing among papers published covering amputated patients. (Sinha, Van Den Heuvel, Arokiasamy, \& Van Dijk, 2014). In 2008, a population survey was conducted in Brazil (Survey of Social Dimensions of Inequalities), where the SF-36 was one of the instruments used allowing the development of normative data adjusted for age and sex for the Brazilian population (Laguardia et al., 2013) serving as a parameter for possible outcome results.

Sociodemographic data were obtained from an electronic medical record, to know the demographic and clinical descriptions of the participants regarding gender, age, marital status, education, place of residence and data related to amputation such as etiology, date of surgery, laterality, amputation site.

Functional Assessment Questionnaire for Amputees (FMA). Validated for Brazilian Portuguese language in 2008 (Kageyama et al., 2008) and is specific for this population. Composed of a series of individual questions to assess the levels of mobility, independence and extent of prosthetic use and to identify factors that may influence these results.

Trinity Amputation and Prosthesis Experience Scale-Revised (TAPES-R): It is intended for multidimensional assessment of quality of life related to people with lower limb amputations adapted to a prosthesis. It is designed to facilitate the examination of the psychosocial processes involved in adapting such a device and the specific demands for its use. It consists of three scales: psychosocial adjustment (general, social and limitation adjustment), activity restriction and satisfaction with the prosthesis (aesthetically and functionally). It explores phantom limb pain experience, residual limb pain, and other non-amputation-related medical conditions (Gallagher, Franchignoni, Giordano, \& MacLachlan, 2010).

Individual administration of these instruments required approximately 1 hour and data were collected in a quiet, private room. The application of the instruments took place between April and August 2017.

\section{Procedures}

This study was approved by the Research Ethics Committee of the institution where the data were collected (CAAE: 53482816.2.0000.0022-Opinion Number: 1.500.841). All individuals who agreed to participate were interviewed individually, signed the Free and Informed Consent Form and responded to the survey instruments.

Descriptive and exploratory data analysis was performed using calculation of proportions for categorical variables; for continuous variables, the mean, median, standard deviation, minimum and maximum were used. Fisher's chi-square test was used to evaluate differences in the distribution of proportions between groups in relation to sociodemographic and clinical variables, while Student's t-test was used to compare variables with two categories; and the $\mathrm{F}$ test, for comparing variables with more than two categories. For the TAPES-R questionnaire, the nonparametric Mann and Kruskal Wallis test was used. For the analyses we considered the significance level of 5\%, and the software used was Stata version 15 . 


\section{Results}

Forty-nine patients were evaluated; $59.2 \%$ were male, $51.0 \%$ single, $40.0 \%$ with higher education; $71.0 \%$ had a job, and $8.0 \%$ were retired. The average age of the participants was 36.4 years, and the age group between 18 and 39 years represented 59.2\%. Average amputation time: 18 years.

Regarding the etiology, patients with traumatic injuries correspond to $40.8 \%$, tumor amputations accounted for $32.7 \%$ of the cases, while $18.4 \%$ were related to congenital deformities that required limb amputation surgery to treat severe deformities. Table 1 shows the complete sociodemographic data of the study population.

Table 1

Sample characterization

\begin{tabular}{|c|c|c|}
\hline \multirow{2}{*}{ Characteristics } & \multicolumn{2}{|c|}{ Participants $(n=49)$} \\
\hline & $n$ & $\%$ \\
\hline \multicolumn{3}{|c|}{ Average age (36.4 years of age / SD 11.1) } \\
\hline 18 to 29 years & 17 & 34.7 \\
\hline 30 to 39 & 12 & 24.5 \\
\hline 40 to 49 & 14 & 28.6 \\
\hline Above 50 & 6 & 12.2 \\
\hline \multicolumn{3}{|l|}{ Gender } \\
\hline Female & 20 & 40.8 \\
\hline Male & 29 & 59.2 \\
\hline \multicolumn{3}{|l|}{ Marital Status } \\
\hline Married & 21 & 42.9 \\
\hline Single & 25 & 51.0 \\
\hline Widowed / separated & 3 & 6.1 \\
\hline \multicolumn{3}{|l|}{ Occupation } \\
\hline Yes & 36 & 73.5 \\
\hline No & 13 & 26.5 \\
\hline \multicolumn{3}{|l|}{ Education } \\
\hline High School & 29 & 59.2 \\
\hline University Education & 20 & 40.8 \\
\hline \multicolumn{3}{|l|}{ Amputation cause } \\
\hline Tumors & 16 & 32.7 \\
\hline Accidents & 20 & 40.8 \\
\hline Congenital & 9 & 18.4 \\
\hline Other & 4 & 8.1 \\
\hline \multicolumn{3}{|l|}{ Laterality } \\
\hline Left & 29 & 59.2 \\
\hline Right & 16 & 32.7 \\
\hline Bilateral & 4 & 8.1 \\
\hline \multicolumn{3}{|l|}{ Amputation type } \\
\hline Above the knee & 34 & 69.4 \\
\hline Below the knee & 15 & 30.6 \\
\hline
\end{tabular}


The domains with the lowest average scores were functional capacity (measuring limitations to perform certain activities) and vitality (measuring the patient's energy and tiredness), with a score of 64.8 and 66.5, respectively. The other domains presented an average score above 70, and the social aspect (evaluating the interference with social activities resulting from physical or emotional problems as a result of the disease or treatment) exhibited the highest score, 80.5. Women had lower ratings than men for all domains. However, in the analysis of SF-36 data regarding gender, cause and type of amputation (above or below the knee), no statistically significant differences were observed between the groups.

\section{Functional assessment questionnaire for amputees - FMA}

Patients used the prosthesis on average 13.1 hours / day (SD =4.3), and patients with tumor amputation used their prosthesis for a shorter period of time than the other patients $(p<0.001)$. In $85 \%$ of the cases they reported being independent to put on and remove the prosthesis. The Locomotor Capabilities Index (LCI) evaluates the patient's independence and mobility in 14 different activities and the highest possible score is 42 . The average presented by this group was 36 , showing partial difficulty.

In the home environment, $94.0 \%$ of the patients used the prosthesis, and out of these $10.0 \%$ reported alternating activities with and without the use of their prosthesis at home. In outdoor settings this percentage of alternation increases to $26.5 \%$, which demonstrates greater insecurity for walking in outdoor settings, preferring the use of locomotion assistance only.

When reviewing the ability to walk with the prosthesis, $67.0 \%$ of the patients had no restriction on gait as evidenced by the answer "I can walk as much as I want"; $16.3 \%$ reported that they can walk approximately 100 steps without stopping and $4.1 \%$, that is, two patients, walk between 30 and 100 steps without stopping. A patient walks between 10 and 30 steps, on a scale where the biggest limitation is "I can't walk with my prosthesis", but no patient reported this extreme situation.

\section{Trinity Amputation and Prosthesis Experience Scale - TAPES- $R$}

Among the 49 respondents, the average score found for the general adjustment and social adjustment was 3.4, and the limitation adjustment 3.0, with the maximum allowed being 4.0 and the higher the score the greater the indication of positive adjustment. In the Activity Restriction Scale (ARS) the average value was 0.7, with the highest possible score being 2.0; high scores are indicative of greater limitation. Regarding satisfaction with aesthetic and functional aspects of the prosthesis, the scores obtained were 6.0 and 10.0, respectively, with the maximum possible value of 9 and 15. For these last items, the higher the assessment, the greater the satisfaction with the prosthesis.

No statistically significant differences were observed when comparing the adjustment scores, activity restriction and satisfaction with the gender variable, except for the limitation adjustment $(p=0.035)$, that is, female scores were higher than male scores, indicating better women's ability to deal with the limitation. Significant difference was observed regarding amputation time with limitation adjustment $(p=0.028)$, which indicates that, in general, the scores of those patients with over 10 years amputation were higher, compared to those up to 10 years amputation time, indicating a better fit.

In the analysis between SF-36 and TAPES-R, it was observed that the general adjustment domain was significantly associated with the emotional aspect $(p=0.017)$, the adjustment to limitation was positively associated with functional capacity, and this association was statistically significant $(p=0.023)$. The The 
activity restriction scores showed statistically significant associations between functional capacity $(p<0.001)$, emotional aspects $(p=0.033)$ and mental health $(p<0.001)$. Aesthetic satisfaction scores were significantly associated with vitality $(p=0.029)$, emotional aspect $(p=0.041)$ and mental health $(p=0.035)$. And finally, functional satisfaction was significantly associated with mental health of SF 36 ( $p=0.029$ ) (Table 2 ).

Table 2

Spearman's correlation coefficient to assess the association between SF-36 instrument domains and TAPES-R

\begin{tabular}{|c|c|c|c|c|c|c|c|c|c|c|c|c|}
\hline \multirow{2}{*}{ SF 36} & \multicolumn{2}{|c|}{ General Adj. } & \multicolumn{2}{|c|}{ Social Adj. } & \multicolumn{2}{|c|}{ Limitation Adj. } & \multicolumn{2}{|c|}{ ARS } & \multicolumn{2}{|c|}{ Aesthetic Satisf. } & \multicolumn{2}{|c|}{ Funct. Satisf. } \\
\hline & rho & $p$-value & rho & $p$-value & rho & $p$-value & rho & $p$-value & rho & $p$-value & rho & $p$-value \\
\hline Funct. Cap. & 0.20 & 0.175 & -0.05 & 0.723 & 0.32 & 0.023 & -0.52 & 0 & 0.24 & 0.103 & 0.21 & 0.152 \\
\hline Physical Asp. & 0.25 & 0.085 & -0.03 & 0.829 & 0.23 & 0.120 & -0.21 & 0.155 & 0.17 & 0.260 & 0.04 & 0.792 \\
\hline Pain & 0.24 & 0.092 & 0.12 & 0.399 & 0.10 & 0.484 & -0.14 & 0.355 & 0.25 & 0.081 & 0.15 & 0.318 \\
\hline Gen. Health & -0.02 & 0.912 & -0.11 & 0.470 & 0.06 & 0.664 & -0.28 & 0.054 & 0.14 & 0.356 & 0.01 & 0.931 \\
\hline Vitality & -0.06 & 0.665 & 0.06 & 0.665 & 0.16 & 0.289 & -0.27 & 0.063 & 0.32 & 0.029 & 0.06 & 0.699 \\
\hline Social Asp. & 0.12 & 0.413 & 0.09 & 0.530 & 0.18 & 0.222 & -0.21 & 0.154 & 0.19 & 0.195 & 0.09 & 0.550 \\
\hline Emot. Asp. & 0.34 & 0.017 & 0.04 & 0.813 & 0.22 & 0.138 & -0.31 & 0.033 & 0.30 & 0.041 & 0.23 & 0.111 \\
\hline Mental Health & 0.07 & 0.650 & 0.16 & 0.281 & 0.23 & 0.119 & -0.51 & 0 & 0.31 & 0.035 & 0.32 & 0.029 \\
\hline $\mathrm{LCl}$ & 0.09 & 0.552 & -0.14 & 0.356 & 0.22 & 0.156 & 0 & 0.995 & -0.10 & 0.504 & 0.01 & 0.960 \\
\hline
\end{tabular}

Note: Adj.: Adjustment; Aesthetic Satisf.: Aesthetic Satisfaction; Funct., Satisf.: Functional Satisfaction; Funct. Cap.: Functional Capacity; Physical Asp.: Physical Aspect; Gen. Health: General Health; Social Asp.: Social Aspects; Emot. Asp.: Emotional Aspects; LCI: Locomotor Capacity Index. ARS: Activity Restriction Scale; rho: Spearman's correlation coefficient; SF-36: Generic Quality of Life Assessment Questionnaire.

\section{Discussion}

Amputation has become one of the problems of today's society, whether it be lifestyle related or due to accident or disease. There is a large number of people who have one or both amputated lower limbs and this situation tends to increase worldwide. It is estimated that $85 \%$ of the amputations that occur in the national scenario affect the lower limbs, and in 2011, the percentage recorded was about $94 \%$ among the amputations performed by the Sistema Único de Saúde (Ministério da Saúde, 2013). People with amputation need to adapt to the loss and changes in the pace of life in interpersonal, social and professional interactions.

There are few studies addressing the quality of life of patients with amputation when compared to other pathologies (Akyol et al., 2013). Previous studies focused their approach primarily on physical functioning and the use of prostheses. However, in the last ten years, new research approaches have been introduced to understand the psychosocial aspects of this population.

The results of this research confirm literature data regarding the predominance of male patients (59.2\% of the studied sample). Studies report that the incidence of amputations according to gender may change according to the regions studied, but global data indicate that it is higher in males (Mohammed \& Shebl, 2014; Zidarov, Swaine, \& Gauthier-Gagnon, 2009).

There is consistency in the study population between the most common amputation causes, trauma and tumor, with the average age of 36.4 years, since amputations associated with those etiologies are more common in younger age groups. Pezzin, Dillingham, and Mackenzie (2000) reported that in the case of traumatic causes $80 \%$ of the amputations occurred before 40 years of age. Amputation secondary to trauma represents an important source of permanent impairment and functional limitation among adolescent and young workers. For the Brazilian population up to 34 years of age, traumatic amputation corresponded to more than $50 \%$ of the sample (Bergo \& Prebianchi, 2018; Silva et al., 2011). 
The average age of samples from other studies generally depends on the population group surveyed, mainly related to the cause of amputation. There are data in the literature showing the mean age at the time of amputation ranging from 25 to 89 years (Asano et al., 2008, Coffey, Gallagher, Desmond, Ryall, \& Wegener, 2014; Sinha et al., 2014;). Among the articles investigated, there is a tendency to search for similar etiological groups, i.e. vascular, traumatic or tumor. Thus, Mohammed and Shebl (2014) reported that the average age of the study group was 48 years, in amputations due to diabetes and vascular complications, which together accounted for $81 \%$ of the sample. In the survey of Asano et al. 2008, the mean age was 62 years for vascular and non-vascular causes. Other authors score the average age of 27.3 years for unilateral amputees and 31.9 years for bilateral amputees (Akarsu, Tekin, Safaz, Göktepe, \& Yazicioğlu, 2013).

Cavalcanti (1994) reported similar data regarding the use of the prosthesis for a shorter number of hours in patients with tumor amputation. Due to the diagnosis, these patients were insecure about the future, represented by the possibility of recurrence of the disease and constant surveillance through exams, besides the structural changes that occur in the body not only due to amputation, but also through treatments such as chemotherapy. Accordingly, these factors interfere in the prosthesis adaptation process, causing greater difficulty for its use.

The 18-year average time after amputation may be one of the reasons for the high scores observed in the SF-36 assessment. Time elapsed since amputation is a predictor of quality of life and is associated with better health outcomes, as cited by Asano et al. (2008) and Amtmann, Morgan, Kim, and Hafner (2015). These data are similar to those obtained by TAPES-R, since patients with longer amputation time (over 10 years) presented better limitation adjustment. Longitudinal follow-up by the rehabilitation team is a positive factor in the evaluation, as it favors adherence and continuity of care regarding the patient and the prosthesis.

Adjustment to amputation was positively correlated with the emotional aspects and the individual's functional capacity, while patients who presented greater activity restriction according to TAPES-R reported lower functional capacity and lower emotional and mental health scores through the SF-36 domains. It is evident that there is a relationship between the instruments in these assessments, since they can capture relevant aspects in the assessment of quality of life, which was also observed in other studies (Coffey et al., 2014; Silva et al., 2011; Sinha et al., 2014). Aesthetic satisfaction with the prosthesis, which includes shape, color and appearance, was positively associated with the mental aspects of SF-36, including vitality, social aspect and mental health. This result reflects the importance given by patients to the aesthetic characteristics of the prosthesis.

The better evaluation of overall fit and functional satisfaction with the prosthesis in patients with below knee amputations is justified by the greater functionality at this level of amputation. This result shows that the patient was adapted to his prosthesis, was able to successfully cope with this aspect of his/her life, and stated (by the scale) that life is complete.

Patients with lower limb amputation had a worse perception of their quality of life, especially with regard to the dimensions of vitality and functional capacity, when compared with the general population. But it is consistent with the normative data for SF-36 established for the Brazilian population by Laguardia et al. (2013). Other studies point to impairment mainly regarding physical aspects and pain (Amtmann et al., 2015; Mohammed \& Shebl, 2014) and the physical function was worse assessed both in the initial evaluation (before rehabilitation) and in the three months follow-up after the training (Zidarov et al., 2009).

The perception of quality of life for patients with amputation is more associated with pain, adaptation to the prosthesis and psychosocial well-being than with clinical or demographic variables such as age, gender, level or cause of amputation (Vaz et al., 2012) which enhances the results of this investigation and no statistical differences were found when correlating SF-36 data with the same variables. 
The better ability of the female population to adjust to the limitation does not reflect a better perception of quality of life, as the scores are lower than those in males, which is confirmed in previous studies (Demet, Martinet, Guillemin, Paysant, \& André, 2003). and is also consistent with data from the Brazilian population. The authors associated the better quality of life assessment by male patients because they are more sociable and mainly due to the larger social support network. Knezevic et al. (2015) report that women have the lowest scores in all the variables tested except for physical functioning.

The scores for the other domains of SF-36 are above 70 points, which characterizes a good perception of quality of life. Fuhrer (2000) attributes what is known as the adaptation level theory that occurs over time after the event. He argues that in circumstances with little modifications for patients, the latter become less and less reactive. Asano et al. (2008) attribute this finding to the phenomenon of change of response, which is the change in assessment from a redefinition of the internal standards and values of the individual. Akarsu et al. (2013) explained this positive evaluation by the use of prostheses in the population studied, since the perception of quality of life correlates positively with the use of this device.

Although assessments are affected by amputation in terms of quality of life and functionality, patients can achieve an acceptable standard of living with a suitable rehabilitation program and prostheses (Akarsu et al., 2013). Studies show the importance of speed in fitting prostheses, least non-adherence occur and point to the scarcity of rehabilitation services after amputation and prosthesis donation (Uustal \& Meier, 2014). Since the time elapsed between amputation and artificial limb adaptation is predictive of the use of these devices, the offering of services aimed at integrating the patient and providing quality services is a demand of individuals with amputation. The number of patients awaiting a prosthesis or even an amputation rehabilitation program in the national scenario is unknown. Adequate quantification of this population is necessary in order to establish rehabilitation programs.

Of utmost importance to the amputated patient is the perception that the rehabilitation process is a lifelong effort and working with a team will provide the necessary guarantees of rehabilitation. But it must also be held responsible for adopting behaviors that promote the health and adequacy of prostheses, such as healthy habits, device care, and body weight maintenance (Uustal \& Meier, 2014).

Currently, an appropriate conduct for professionals dealing with this population is the information and management of expectations regarding the selection and adaptation of prostheses. Desired models are often inaccessible and unsuitable for that particular individual, either for financial reasons or because of one's own profile, related to mobility and recovery possibilities. The health professionals involved should be aware of how this advertising interferes with expectation and experience and the impact on rehabilitation when planning the necessary care (Murray \& Forshaw, 2014).

For outcome evaluation in patients with amputation, there is a large number of measures in place that evaluate outcomes, but there is no gold standard. There is little agreement on which measure to use and when. However, there are instruments that have their use most frequently reported in the literature, such as SF-36 (Condie, Scott, \& Treweek, 2006) and more specifically the TAPES-R.

It is highly recommended to use TAPES-R in this population. Not only will it allow an objective assessment of the adaptation to amputation and to the use of an artificial limb after amputation, but it will also indicate to what extent quality of life can be improved (Sinha et al., 2014).

\section{Conclusion}

As a conclusion of this survey, the time since amputation, male gender and below knee amputations were predictors of a better perception of quality of life and better adjustment to amputation. 
A possible limitation of this study is its cross-sectional character. Longitudinal studies are suggested for this population, as this will allow a better description of the variation in quality of life over time. And, because of the large number of factors that can influence changes in quality of life and the importance of understanding the significance of these factors for the individuals concerned, a methodology that encompasses both quantitative and qualitative research should be used simultaneously with the analysis of the nature of their interrelationships.

The objective of this study is to evaluate patients with lower limb amputation who are using prostheses. Data cannot be generalized for the population that does not have access to this assisting technology device, as the prosthesis can positively impact the quality of life of its users. In addition, an impactful subject, but little studied for the patient with amputation, is the return of the patient to the job market, and studies that address this issue are needed.

\section{Contributors}

D.R. MATOS was responsible for the conception and design of the study, data collection and interpretation, discussion of results, review and final approval of the article. J.F. NAVES participated in the collection, analysis and interpretation of data and revision of the text. T.C.C.F. ARAUJO is the study advisor, responsible for the final review of the article.

\section{References}

Akarsu, S., Tekin, L., Safaz, I., Göktepe, A. S., \& Yazicioğlu, K. (2013). Quality of life and functionality after lower limb amputations: Comparison between uni - vs. bilateral amputee patients. Prosthetics and Orthotics International, 37 , 9-13. http://dx.doi.org/10.1177/0309364612438795

Akyol, Y., Tander, B., Goktepe, A. S., Safaz, I., Kuru, O., \& Tan, A. K. (2013). Quality of life in patients with lower limb amputation: Does it affect post-amputation pain, functional status, emotional status and perception of body image? Journal of Musculoskeletal Pain, 21(4), 334-340. http://doi.org/dx.10.3109/10582452.2013.851761

Amtmann, D., Morgan, S. J., Kim, J., \& Hafner, B. J. (2015). Health-related profiles of people with lower limb loss. Archives of Physical Medicine and Rehabilitation, 96(8), 1474-1483. http://dx.doi.org/10.1016/j.apmr.2015.03.024

Asano, M., Rushton, P., Miller, W. C., \& Deathe, A. D. (2008). Predictors of quality of life among individuals who have a lower limb amputation. Prosthetics and Orthotics International, 32(2), 231-243. http://dx.doi. org/10.1080/03093640802024955

Barbosa, B. M. B., Monteiro, R. A., Sparano, L. F., Bareiro, R. F. N., Passos, A. D. C., \& Engel, E. E. (2016). Incidence and causes of lower-limb amputations in the city of Ribeirão Preto from 1985 to 2008: Evaluation of the medical records from 3.274 cases. Revista Brasileira de Epidemiologia, 19(2), 317-325. http://dx. doi.org/10.1590/1980-5497201600020009

Bergo, M. F. C., \& Prebianchi, H. B. (2018). Emotional aspects present in the lives of amputees: A literature review. Revista Psicologia: Teoria E Prática, 20(1), 47-60.

Cavalcanti, M. C. T. (1994). Adaptação psicossocial à amputação de membros. Jornal Brasileiro de Psiquiatria, 43(2), 71-74. http://dx.doi.org/10.5935/1980-6906/

Ciconelli, R. M., Ferraz, M. B., Santos, W., Meinão, I., \& Quaresma, M. R. (1999). Tradução para a língua portuguesa e validação do questionário genérico de avaliação de qualidade de vida SF-36 (Brasil SF-36). Revista Brasileira de Reumatologia, 39(3), 143-150.

Coffey, L., Gallagher, P., Desmond, D., Ryall, N., \& Wegener, S. T. (2014). Goal management tendencies predict trajectories of adjustment to lower limb amputation up to 15 months post rehabilitation discharge. Archives of Physical Medicine and Rehabilitation, 95(10), 1895-1902. http://dx.doi.org/10.1016/j.apmr.2014.05.012

Condie, E., Scott, H., \& Treweek, S. (2006). Lower limb prosthetic outcome measures: A review of the literature 1995 to 2005. Journal of Prosthetics and Orthotics, 18(1), 13-45. http://dx. doi.org/10.1097/00008526-200601001-00004

Counted, V., Possamai, A., \& Meade, T. (2018). Relational spirituality and quality of life 2007 to 2017: An integrative research review. Health and Quality of Life Outcomes, 16(1), 1-18. http://dx.doi.org/10.1186/s12955-018-0895-x 
Davie-Smith, F., Coulter, E., Kennon, B., Wyke, S., \& Paul, L. (2017). Factors influencing quality of life following lower limb amputation for peripheral arterial occlusive disease: A systematic review of the literature. Prosthetics and Orthotics International, 41(26), 537-547. http://dx.doi.org/10.1177/0309364617690394

Demet, K., Martinet, N., Guillemin, F., Paysant, J., \& André, J. M. (2003). Health related quality of life and related factors in 539 persons with amputation of upper and lower limb. Disability and Rehabilitation, 25(9), 480-486. http://dx.doi. org/10.1080/0963828031000090434

Fuhrer, M. J. (2000). Subjectifying quality of life as a medical rehabilitation outcome. Disability and Rehabilitation, 22(11), 481-489. http://dx.doi.org/10.1080/096382800413961

Gallagher, P., Desmond, D., \& MacLachlan, M. (2005). A guide to the trinity amputation and prosthesis experience scales Revised. 1-10. Retrieved from www.psychoprosthetics.ie

Gallagher, P., Franchignoni, F., Giordano, A., \& MacLachlan, M. (2010). Trinity amputation and prosthesis Scales: A psychometric assessment using classical test theory and rasch analysis. American Journal of Physical Medicine and Rehabilitation, 89(6), 487-496. http://dx.doi.org/10.1097/PHM.0b013e3181dd8cf1

Holzer, L. A., Sevelda, F., Fraberger, G., Bluder, O., Kickinger, W., \& Holzer, G. (2014). Body image and self-esteem in lower-limb amputees. Plos One, 9(3), e92943. http://dx.doi.org/10.1371/journal.pone.0092943

Instituto Brasileiro de Geografia e Estatística. (2011). Censo Demográfico 2010: Características gerais da população, religião e pessoas com deficiencia, segundo a situação do domicílio e grupos de idade. Rio de Janeiro: Autor. Recuperado de https://biblioteca.ibge.gov.br/visualizacao/livros/liv49230.pdf

Kageyama, E. R. O., Yogi, M., Sera, C. T. N., Yogi, L. S., Pedrinelli, A., \& Camargo, O. P. (2008). Validação da versão para a língua portuguesa do questionário de medida funcional para amputados (functional measure for amputees questionnaire). Fisioterapia e Pesquisa, 15(2), 164-171.

Knezevic, A., Salamon, T., Milankov, M., Ninkovic, S., Jeremic-Knezevic, M., \& Tomasevic-Todorovic, S. (2015). Assessment of quality of life in patients after lower limb amputation. Medicinski Pregled, 68(3-4), 103-108. http://dx.doi. org/10.2298/MPNS1504103K

Laguardia, J., Campos, M. R., Travassos, C., Najar, A. L., Anjos, L. A., \& Vasconcellos, M. M. (2013). Brazilian normative data for the Short Form 36 questionnaire, version 2. Revista Brasileira de Epidemiologia, 16(4), 889-897. http://dx.doi. org/10.1590/S1415-790X2013000400009

Ministerio da Saúde (Brasil). (2013). Diretrizes de atenção à pessoa amputada. Brasília: Autor. Recuperado de http:// bvsms.saude.gov.br/bvs/publicacoes/diretrizes_atencao_pessoa_amputada

Mohammed, S. A., \& Shebl, A. M. (2014). Quality of Life among egyptian patients with upper and lower limb amputation: Sex differences. Advances in Medicine, 1-8. http://dx.doi.org/10.1155/2014/764323

Murray, C. D., \& Forshaw, M. J. (2014). "Look and feel your best": Representations of artificial limb users in prosthetic company advertisements. Disability and Rehabilitation, 36(2), 170-176. http://dx.doi.org/10.3109/09638288.2013. 782365

Panzini, R. G., Mosqueiro, B. P., Zimpel, R. R., Bandeira, D. R., Rocha, N. S., \& Fleck, M. P. (2017). Quality-of-life and spirituality. International Review of Psychiatry, 29(3), 263-282. http://dx.doi.org/10.1080/09540261.2017.1285553

Pasquina, A. J. C., \& Sheehan, T. P. (2015). Ethics in rehabilitation: Access to prosthetics and quality care following amputation. The AMA Journal of Ethic, 17(6), 535-546. http://dx.doi.org/10.1001/journalofethics.2015.17.6.stas1-1506

Pasquina, P. F., Miller, M., Carvalho, A. J., Corcoran, M., Vandersea, J., Johnson, E., \& Chen, Y. T. (2014). Special considerations for multiple limb amputation. Current Physical Medicine and Rehabilitation Reports, 2(4), 273-289. http://dx.doi.org/10.1007/s40141-014-0067-9

Pezzin, L. E., Dillingham, T. R., \& MacKenzie, E. J. (2000). Rehabilitation and the long-term outcomes of persons with trauma-related amputations. Archives of Physical Medicine and Rehabilitation, 81, 292-300. http://dx.doi.org/0003-9 993/00

Pocnet, C., Antonietti, J. P., Strippoli, M. P. F., Glaus, J., Preisig, M., \& Rossier, J. (2016). Individuals' quality of life linked to major life events, perceived social support, and personality traits. Quality of Life Research, 25(11), 2897-2908. http://dx.doi.org/10.1007/s11136-016-1296-4

Schaffalitzky, E., Gallagher, P., Desmond, D., \& MacLachlan, M. (2010). Adaptation to amputation and prosthesis use. In C. Murray (Ed.), Amputation, prosthesis use, and phantom pain: An interdisciplinary perspective (pp.65-79). New York: Springer. http://dx.doi.org/10.1007/978-0-387-87462-3_5

Schnur, D., \& Meier, R. H. (2014). Amputation surgery. Physical Medicine and Rehabilitation Clinics of North America, 25(1), 35-43. http://dx.doi.org/10.1016/j.pmr.2013.09.013 
Silva, R., Rizzo, J. G., Gutierres Filho, P. J. B., Ramos, V., \& Deans, S. (2011). Physical activity and quality of life of amputees in southern Brazil. Prosthetics and Orthotics International, 35(4), 432-8. http://dx.doi.org/10.1177/0309364611425093

Sinha, R., Van Den Heuvel, W. J. A., Arokiasamy, P., \& Van Dijk, J. P. (2014). Influence of adjustments to amputation and artificial limb on quality of life in patients following lower limb amputation. International Journal of Rehabilitation Research, 37(1), 74-79. http://dx.doi.org/10.1097/MRR.0000000000000038

Suckow, B. D., Goodney, P. P., Nolan, B. W., Veeraswamy, R. K., Gallagher, P., Cronenwet, J. L., \& Kraiss, L. W. (2015). Domains that determine quality of life in vascular amputees. Annals of Vascular Surgery, 29(4), 722-30. http://dx.doi. org/10.1016/j.avsg.2014.12.005

Uustal, H., \& Meier, R. H. (2014). Pain issues and treatment of the person with an amputation. Physical Medicine and Rehabilitation Clinics of North America, 25(1), 45-52. http://dx.doi.org/10.1016/j.pmr.2013.09.008

Vaz, M., Roque, V., Pimentel, S., Rocha, A., \& Duro, H. (2012). Psychosocial characterization of a Portuguese lower limb amputee population. Acta Medica Portuguesa, 25(2), 77-82.

Ware, J. E., \& Sherbourne, C. D. (1992). The MOS 36- item short-form health survey (SF-36) I: Conceptual framework and item selection. Medicine and Care, 30(6), 473-483.

Wurdeman, S. R., Stevens, P. M., \& Campbell, J. H. (2018). Mobility Analysis of AmpuTees (MAAT I): Quality of life and satisfaction are strongly related to mobility for patients with a lower limb prosthesis. Prosthetics and Orthotics International, 42(5), 498-503. http://dx.doi.org/10.1177/0309364617736089

Zidarov, D., Swaine, B., \& Gauthier-Gagnon, C. (2009). Quality of life of persons with lower-limb amputation during rehabilitation and at 3-month follow-up. Archives of Physical Medicine and Rehabilitation, 90(11), 634-645. http:// dx.doi.org/10.1016/j.apmr.2008.11.003

Received: April 23, 2019

Final version: September 10, 2019

Approved: October 22, 2019 